\title{
Clinical responses following inspiratory muscle training in exercise-induced laryngeal obstruction
}

\author{
Astrid Sandnes ${ }^{1,6}$ (D) Tiina Andersen ${ }^{2,8,10} \cdot$ Hege Havstad Clemm ${ }^{3,6} \cdot$ Magnus Hilland $^{4} \cdot$ John-Helge Heimdal ${ }^{4,5,7}$. \\ Thomas Halvorsen ${ }^{3,6,9}$. Ola Drange Røksund ${ }^{3,4,10} \cdot$ Maria Vollsæter $^{3,6,8}$
}

Received: 21 October 2021 / Accepted: 3 December 2021 / Published online: 26 December 2021

(c) The Author(s) 2021

\begin{abstract}
Purpose Exercise-induced laryngeal obstruction (EILO) is relatively common in young people. Treatment rests on poor evidence; however, inspiratory muscle training (IMT) has been proposed a promising strategy. We aimed to assess laryngeal outcomes shortly after IMT, and to compare self-reported symptoms with a control group 4-6 years later.

Methods Two groups were retrospectively identified from the EILO-register at Haukeland University Hospital, Norway; one group had received only information and breathing advice (IBA), and another additionally IMT (IBA + IMT). At diagnosis, all participants performed continuous laryngoscopy during exercise (CLE), with findings split by glottic and supraglottic scores, and completed a questionnaire mapping exercise-related symptoms. After 2-4 weeks, the IBA + IMT-group was reevaluated with CLE-test. After 4-6 years, both groups were re-assessed with a questionnaire.

Results We identified 116 eligible patients from the EILO-register. Response rates after 4-6 years were 23/58 (40\%) and $32 / 58(55 \%)$ in the IBA and IBA + IMT-group, respectively. At diagnosis, both groups rated symptoms similarly, but laryngeal scores were higher in the IBA + IMT-group $(P=0.003)$. After $2-4$ weeks, $23 / 32$ in the IBA + IMT-group reported symptom improvements, associated with a decrease of mainly glottic scores $(1.7-0.3 ; P<0.001)$, contrasting unchanged scores in the $9 / 32$ without symptom improvements. After 4-6 years, exercise-related symptoms and activity levels had decreased to similar levels in both groups, with no added benefit from IMT; however, full symptom resolution was reported by only 8/55 participants.
\end{abstract}

Conclusion Self-reported EILO symptoms had improved after 4-6 years, irrespective of initial treatment. Full symptom resolution was rare, suggesting individual follow-up should be offered.

Keywords Laryngeal obstruction $\cdot$ Exercise $\cdot$ Dyspnea $\cdot$ Stridor $\cdot$ Inspiratory muscle training

Abbreviations

CI Confidence interval

CLE test Continuous laryngoscopy exercise test

EILO Exercise induced laryngeal obstruction

Astrid Sandnes

astrid.sandnes@sykehuset-innlandet.no

1 Department of Internal Medicine, Innlandet Hospital Trust, Gjøvik, Norway

2 Department of Physiotherapy, Haukeland University Hospital, Bergen, Norway

3 Department of Pediatrics, Haukeland University Hospital, Bergen, Norway

4 Department of Otolaryngology/Head and Neck Surgery, Haukeland University Hospital, Bergen, Norway

5 Department of Surgery, Haukeland University Hospital, Bergen, Norway
IBA Information and breathing advice (instructed by a physician)

IMT Inspiratory muscle training

$\mathrm{Pi}_{\max } \quad$ Maximal inspiratory mouth pressure

6 Institute of Clinical Medicine, University of Bergen, Bergen, Norway

7 Institute of Surgical Science, University of Bergen, Bergen, Norway

8 Thoracic Department, Norwegian Advisory Unit on Home Mechanical Ventilation, Bergen, Norway

9 Department of Sports Medicine, Norwegian School of Sport Sciences, Oslo, Norway

10 The Faculty of Health and Social Sciences, Western Norway University of Applied Sciences, Bergen, Norway 


\section{Introduction}

Exercise-induced laryngeal obstruction (EILO) is an umbrella term describing inappropriate and transient adduction of laryngeal structures during exercise causing breathlessness and/or stridor [1], and is reported to affect $5-7 \%$ of young people $[2,3]$. Symptoms typically peak at maximal exercise or immediately after, with respiratory distress, prolonged inspiration, a chocking sensation, and sometimes panic [4]. Symptoms of EILO are sometimes interpreted as exercise-induced asthma (EIA) [1, 5], a situation likely leading to mismanagement of both conditions [6]. Besides limiting otherwise healthy adolescents in their physical activities [6,7], undiagnosed respiratory problems might reduce quality of life and disrupt participation on sports arenas [8,9]. Individuals with EILO represent a diverse group and range from sedentary youngsters who might be affected in light activities, to top athletes whose performance is affected only when ventilation requirements are very high [10].

EILO is diagnosed by continuously visualizing the larynx with a flexible laryngoscope during maximal exercise (continuously laryngoscopy exercise test, CLE-test) [11]. Laryngeal obstruction can occur at the supraglottic or glottic level or involve both levels, and one may differentiate between EILO subgroups with mainly glottic or supraglottic obstruction, possibly associated with different causal mechanisms [12]. Laryngeal findings can be graded according to severity, using, e.g., CLE-scores, where higher scores indicate more obstruction $[12,13]$. However, the perception of breathlessness is subjective [14, 15], and associations with CLE-scores are poorly described [16]. Treatment of EILO is largely based on empirical data [4, 12]. Most conservative strategies focus on making patients properly aware of their breathing pattern, structured breathing advice, and various breathing practices [1, 17-19]. Tailoring treatment modalities based on EILO subgroups or CLE-scores is still based on weak evidence, except for severe supraglottic EILO where supraglottoplasty has been reported successful [20].

Inspiratory muscle training (IMT) has been proposed a promising tool to treat EILO. Preliminary research suggest that IMT primarily improve the glottic component; however, randomized controlled studies are required to confirm these reports [22, 24-28]. IMT is based on breathing exercises performed with a resistance applied during inspiration, focusing on enhanced coordination and strengthening of the inspiratory muscles [21]. The effect might rest on the phasic relationship that exist between the diaphragm and the main laryngeal abductor (the posterior cricoarytenoid muscle); the former contracting immediately before the latter [23].

We aimed to assess improvements of self-reported symptoms and laryngeal outcomes in EILO shortly after treatment with standardized information and breathing advice (IBA) plus 6 weeks of IMT. After 4-6 years, we conducted a questionnaire-based follow-up in the same individuals, comparing their self-reported symptoms with a control group with EILO who had only received IBA.

\section{Methods}

\section{The EILO-register and CLE-test}

Since 2013, more than 99 percent of patients diagnosed with EILO at our institution have been consecutively enrolled in the Bergen EILO-register, where background demographics and self-reported questionnaires are stored together with data from the CLE-test, which contains laryngoscopy findings from rest to peak exercise, a soundtrack, and a film of the upper part of the body. CLE-tests are routinely performed as described previously [11], for details please see Fig. 1. The CLE-test permits grading of laryngeal obstruction from 0 (complete patency) to 3 (almost complete closure) at the glottic and supraglottic level (the CLE-score, see Fig. 2) [13]. The CLE recordings were rated in retrospect and in random order by two experienced reviewers who were both blinded to the identity of the person and the clinical situation (i.e., if the film was obtained at diagnosis or $2-4$ weeks after IBA+IMT). The findings were split by supraglottic and glottic scores, and disagreements were solved by consensus.

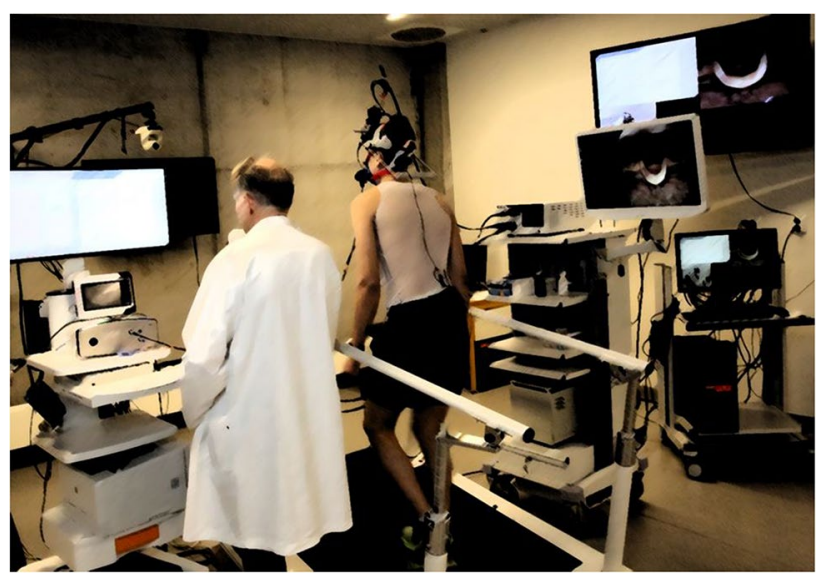

Fig. 1 The continuous laryngoscopy exercise (CLE) test. An integrated setup with a trans-nasal flexible fiberoptic laryngoscope (Olympus ENF-P3 ${ }^{\circledR}$, Tokyo, Japan), diameter $3.5 \mathrm{~mm}$, introduced after applying a decongestive nasal spray (Rhinox ${ }^{\circledR}$ ) and local anesthesia (Xylocaine ${ }^{\circledR}$ ), and secured in a position allowing for a good view of the laryngeal entrance, including both supraglottic structures and the vocal folds. Continuous video recordings from the laryngoscope, a film of the upper part of the body, and breath sounds are obtained simultaneously throughout a maximal cardiopulmonary exercise test, and stored in one single file for later evaluation. The method is widely used and applied as previously described [11] 
Fig. 2 Grading system of laryngeal obstruction according to Maat et al. [13]. Reprinted by permission from Springer Nature. European Archives of Oto-Rhino-Laryngology, Copyright @ 2009 , Dec;266(12):1929-36. Epub 2009 Jul 8 (https://doi.org/10. 1007/s00405-009-1030-8)

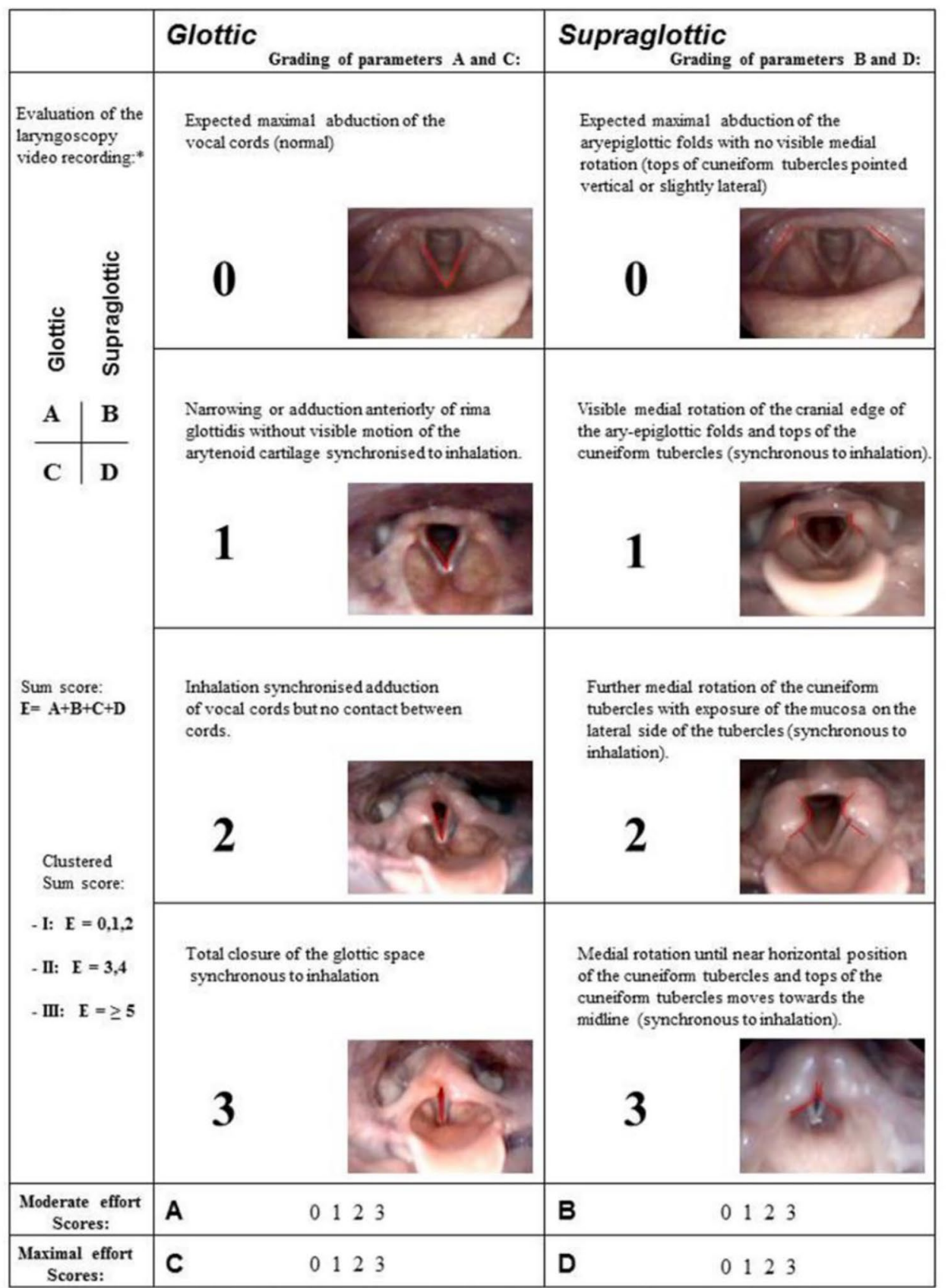

*The scores at each level (glottic $(A$ and $C)$ and supraglottic $(B$ and $D)$ ) were assessed at moderate $(A, B)$ (when subject started to run) and at maximal effort $(C, D)$ (just before the subject stopped running at the treadmill); all four numbers (A-D) were noted together with a sum score (E) for each test/subject.

\section{Participants and study design}

The participants were retrospectively identified from the Bergen EILO-register, based on access to a diagnostic CLE-test performed during 2013-2015, followed by treatment with standardized IBA plus 6-weeks of IMT, and a subsequent re-evaluation with CLE after 2-4 weeks (IBA + IMT-group). Only patients with a documented compliance to the IMT training exceeding $70 \%$, assured by the memory card of the device, were included. A control group was identified, based on a diagnostic CLE-test and treatment with only IBA during 2013-2014 (IBA-group). A questionnaire mapping self-reported symptoms were completed by all participants at diagnosis and mailed to both groups at a follow-up 4-6 years later (Fig. 3).

The study was approved by the Committee on Medical Research Ethics of Western Norway (REK number 2016/1898). Informed written consent was obtained from participants and/or guardians. 
Fig. 3 Overview of study design and participants included in the study of subjects diagnosed with exercise-induced laryngeal obstruction (EILO) at the outpatient clinic at Haukeland University Hospital in Bergen, Norway between 2013 and 2015. All participants received information and physician guided breathing advice (IBA), and one group additionally received inspiratory muscle training (IMT) at diagnosis

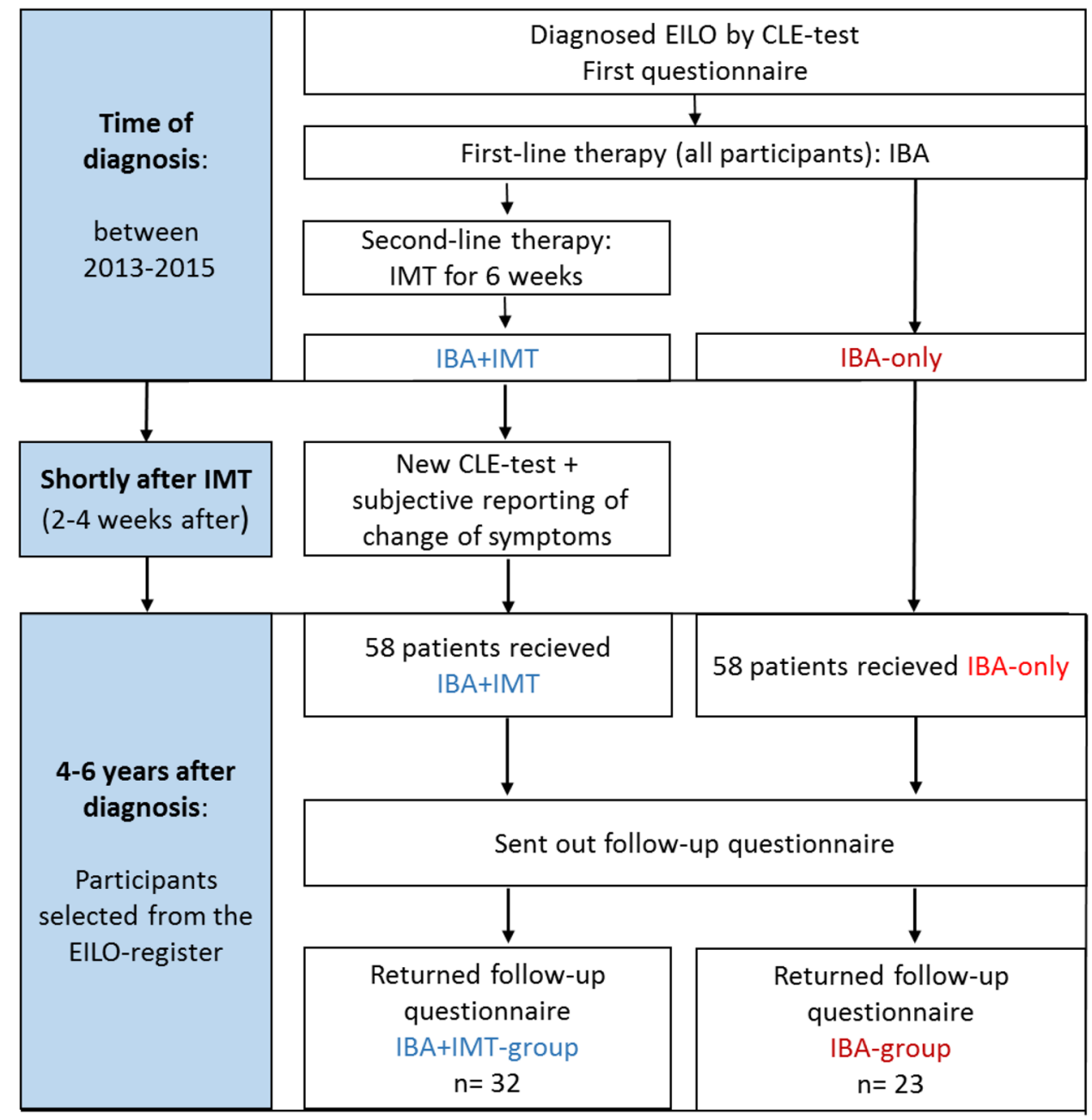

\section{Information and breathing advice (IBA) with biofeedback}

Standardized IBA is provided by physicians as first line treatment to all patients diagnosed with EILO at our institution. IBA consists of information about the diagnosis, its benign nature and structured breathing advice while observing the laryngeal responses on the monitor (biofeedback). The breathing advice entails guidance in posture, relaxation of the shoulder girdle, diaphragmatic breathing, avoidance of noisy breathing/stridor during exercise, early recognition of initial signs of breathing problems, and regaining control when such signs arise. Patients are encouraged to maintain their level of physical activity, and to practice breathing advice while exercising.

After the IBA session, patients were (and still are) assigned to second-line treatment depending on the severity of the laryngeal obstruction and the motivation of the patient. At the time the participants were diagnosed, second-line treatment consisted of either speech therapy or inspiratory muscle training (IMT) for 6 weeks. As no hard data existed to prioritize between these two modalities, they were used interchangeably, based on availability. Only those enrolled in IMT treatment were relevant to this particular follow-up study.

\section{Inspiratory muscle training (IMT)}

Patients found eligible for IMT were recruited at time of diagnosis, after the IBA had been provided. IMT instructions were then given, and standardized training was performed over the following 6 weeks, using a resistive loading device, Respifit $\mathrm{S}^{\circledR}$ (Biegler GmbH, Mauerbach, Austria), for details please see Online resource 1 , or a previous communication [27]. The protocol alternates between two modes of resistance; A) inspiratory resistance $\geq 80 \%$ of maximum produced mouth pressures $\left(\mathrm{Pi}_{\max }\right)$ [29], and B) inspiratory resistance: $60-80 \%$ of $\mathrm{Pi}_{\max }$. Evaluation of IMT was performed 2-4 weeks after the 6-week training period with a second CLE-test. 


\section{Questionnaire}

The participants (and/or guardians) completed a questionnaire at diagnosis, then 2-4 weeks after IMT (only the IBA + IMT-group), and at follow-up 4-6 years after diagnosis (all participants). The questionnaire (Online resource 2) covered medical history, development (Q-A.1-8) and significance (Q-B.1-2) of the breathing problem, symptom perception (Q1-18) and level of physical activity. A reminder was sent after 2 months to those who did not respond.

\section{Study outcomes and statistical methods}

This was a register-based descriptive follow-up study with self-reported symptoms as primary outcome, supplemented with CLE-scores obtained by a new CLE-test 2-4 weeks after treatment in the IBA + IMT-group. A secondary outcome was self-reported level of physical activity. CLEscores are by nature categorical [13], but are reported as means with $95 \%$ confidence intervals (CI) which is considered to provide more information than medians and interquartile ranges when there are few categories [30]. Descriptive data was presented with counts and percentages. After checking for normality, the symptom scores (at diagnosis and follow-up) were compared with t-tests and one-way ANOVA, as appropriate. Mann-Whitney $U$ test was applied for non-normally distributed data. Analyses were performed with SPSS version 24 (SPSS, Chicago, IL, USA). A $P$ value $<0.05$ was considered significant.

\section{Results}

\section{Participants}

Fifty-eight participants from the EILO-register were eligible for inclusion in the IBA + IMT-group, of whom 32/58 (55\%) participants returned the questionnaire 4-6 years after diagnosis. Correspondingly, 58 participants, consecutively treated only with IBA, were approached as controls, of whom 23/58 (40\%) participants returned the questionnaire (Fig. 3). The two groups had similar ratings of self-reported symptoms at diagnosis. Two participants in the IBA-group had to be excluded, as they had later been treated with supraglottoplasty. Demographics and symptoms at diagnosis did not differ between responders and non-responders (Online resource 3), except that non-responders in the IBA + IMTgroup reported less problems when physically active (Q12). Mean (range) follow-up time was 59 (46-73) and 60 (54-71) months in the IBA and IBA + IMT-group, respectively. Demographic data are listed in Table 1. Although symptom scores were similar at diagnosis, CLE-scores were higher in the IBA + IMT-group $(P=0.003)$, which was as expected in a group selected for second-line therapy. Thirteen of the 32 IBA + IMT-group responders took part in a previously published study on IMT [27]. None reported any side effects at follow-up after training with IMT.

\section{Re-evaluation, 2-4 weeks after IMT (IBA + IMT-group only)}

Symptom scores had improved in most participants (23/32; $72 \%)$, and improvements were associated with reduced CLE-scores, particularly at the glottic level $(P<0.001)$. In participants without subjective improvement $(9 / 32 ; 18 \%)$, the CLE-scores were unchanged (P.565) (Table 2, Fig. 4).

\section{Follow-up 4-6 years after diagnosis (all participants):}

\section{The significance of the breathing problem and the severity of the symptoms}

Most questionnaire items describing symptom severity had improved, with no differences between the two treatment groups (Table 3). There were no associations between a positive response at the re-evaluation 2-4 weeks after IBA+IMT treatment and symptom descriptions at the 4-6-year followup. Only five (16\%) in the IBA + IMT-group and three (13\%) in the IBA-group stated, "I no longer have a breathing problem" (Q-A.8). Seven (22\%) in the IBA + IMT-group and 9 $(39 \%)$ in the IBA-group stated, "the problem is unchanged and bothers me as much as before" (Q-A.2). One in the IBA + IMT-group reported worsening of the breathing problem (Q-A.1) (Table 4). In both groups, the impact of the breathing problem was reduced when "considering life overall" (Q-B.2), and the number responding positively to the question "I can control my symptoms when I get them" (Q18) was numerically increased; although significant only in the IBA + IMT-group ( $P$ 0.018) (Table 3).

\section{Physical activity level at follow-up}

Twenty-three (73\%) in the IBA + IMT-group and 12 (52\%) in the IBA-group reported reduced level of physical activity $(P$ 0.803). Thirteen $(41 \%)$ in the IBA + IMT-group and 10 $(44 \%)$ in the IBA-group reported "less breathing problems because I am less active" (Q-A.4) (Table 4). Eight (25\%) in the IBA+ IMT-group and five (22\%) in the IBA-group still reported "nearly always or always" to the question "I have breathing problems when I am physically active" (Q12). However, most participants in both the IBA + IMT (87\%) and the IBA (65\%) group answered "never" to the question "Symptoms prevent me from exercising" (Q14) (Table 3). 
Table 1 Demographic data obtained at diagnosis from subjects identified with exercise induced laryngeal obstruction (EILO) at the outpatient clinic at Haukeland University Hospital in Norway

\begin{tabular}{|c|c|c|c|}
\hline & \multicolumn{2}{|l|}{ Participants $^{\mathrm{a}}$} & \multirow{2}{*}{$\begin{array}{l}\text { Group com- } \\
\text { parisons at } \\
\text { diagnosis } \\
P \text { value }\end{array}$} \\
\hline & $\mathrm{IBA}+\mathrm{IMT}$ & IBA & \\
\hline Number (percent females) & $32(90)$ & $23(56)$ & \\
\hline $\mathrm{BMI}$ at diagnosis, mean $(95 \% \mathrm{CI})$ & $21(20-22)$ & $21(20-22)$ & 0.993 \\
\hline Age symptom debut, mean (range) & $12.6(1.5-20)$ & $10.5(5-15)$ & 0.052 \\
\hline Age at diagnosis, mean (range) & $17.5(10-30)$ & $15.2(12-21)$ & 0.019 \\
\hline Age at follow-up, mean (range) & $22.7(15-36)$ & $20.4(17-26)$ & 0.036 \\
\hline FEV $1, \%$ of predicted $(95 \% \mathrm{CI})$ & $112 \%(108-116)$ & $110 \%(106-114)$ & 0.936 \\
\hline EIA diagnoses at first visit; yes/no/unsure $(n)$ & $3 / 17 / 12$ & $3 / 16 / 4$ & \\
\hline Asthma medication before referral; yes/no $(n)$ & $6 / 15$ & $8 / 21$ & \\
\hline Activity hours, median per week, at diagnosis vs. follow-up & $\geq 7$ vs. $4-6^{*}$ & $\geq 7$ vs. $4-6^{*}$ & 0.667 \\
\hline Level of sports activity at diagnosis vs. at follow-up $(n)$ & & & 0.803 \\
\hline No organized activity & 2 vs. $19^{*}$ & 3 vs. $13^{*}$ & \\
\hline Competing at local/regional level & 16 vs. $7 *$ & 16 vs. $6^{*}$ & \\
\hline Competing at national level & 10 vs. $4^{*}$ & 3 vs. 3 & \\
\hline Competing at international level & 4 vs. 2 & 0 vs. 0 & \\
\hline
\end{tabular}

All subjects had received information and breathing advice (IBA) and one group had additionally received inspiratory muscle training (IBA + IMT group). Data obtained at diagnosis and at follow-up after 4-6 years

$I M T$ inspiratory muscle training, IBA information and breathing advice, $C I$ confidence interval

$P$ values were calculated using Students t-tests or Mann-Whitney- $U$-test as appropriate

*Indicates a significant change in activity level from diagnosis to follow-up after 4-6 years

${ }^{a}$ Items where numbers do not add up to the total group number are due to missing answers on questionnaire

\section{Individual differences at follow-up}

There were extremes as regards self-reported symptoms at follow-up in both groups and in both directions; some reported to be symptom-free, and some reported still being severely affected. For example, in both treatment groups, responses at follow-up to the question "How much do your breathing problems effect you?" could vary from "not at all or a little" to "crippling" (Q-B.2). None in the IBA + IMTgroup and two in the IBA-group reported panic (Q11) or to be afraid when symptoms arise (Q15).

\section{Discussion}

This is the first follow-up study aiming to evaluate selfreported symptoms and CLE-scores after IMT used to treat EILO. We found that self-reported symptoms and laryngeal findings had improved in most participants shortly after treatment with standardized IBA plus 6 weeks of IMT. Symptom improvement was associated with improved CLE-score, particularly at the glottic level. After 4-6 years, self-reported symptoms had improved to similar levels both in the IBA+IMT-group and in the IBA-group, irrespective of laryngeal findings and symptom reports shortly after the
IMT. Symptom resolution was rare, and respiratory problems still disturbed most participants during exercise. The level of physical activity had decreased in most participants during the 4-6-year follow-up.

\section{Strengths and limitations of the study}

The major strengths of the study were enrolment of participants who were considered typical of patients seeking treatment for EILO, diagnostic accuracy ensured by a CLE-test performed in all participants at inclusion [1], and that a control group treated with IBA only were included for comparison at the 4-6-year follow-up. Recruitment was based on retrospective identification of all eligible participants from a nationwide EILO-register with high cover ratio. Major weaknesses were that information at the 4-6-year follow-up was based only on self-reports, the retrospective nature of the study and therefore a risk of recall bias, no randomization of participants between the two treatment groups, a high attrition rate, and relatively few participants. The lack of a control group at the time when the short-term influence of IMT was evaluated, prevents us from reliably ascribing the early changes in participants using IMT to the IMT itself-since IBA had also been provided. The questionnaire was not a validated instrument in 
Table 2 Laryngeal obstruction (evaluated by CLE-scores) in subjects diagnosed with exercise induced laryngeal obstruction (EILO) at Haukeland University Hospital

\begin{tabular}{|c|c|c|c|c|c|}
\hline & \multicolumn{3}{|l|}{$\mathrm{IBA}+\mathrm{IMT}$} & \multicolumn{2}{|l|}{ IBA } \\
\hline & Subjective improvement & No subjective improvement & $P$ value $^{\mathrm{b}}$ & $n=23$ & $P$ value $^{\mathrm{c}}$ \\
\hline & $2-4$ weeks after IMT $(n=23)$ & 2-4 weeks after IMT $(n=9)$ & & & \\
\hline CLE-scores (total) at diagnosis & $3.7(3.2-4.1)$ & $3.9(3.1-4.7)$ & 0.565 & $2.7(2.3-3.2)$ & 0.003 \\
\hline Glottic score & $1.7(1.3-2.0)$ & $1.9(1.4-2.6)$ & 0.444 & $1.2(0.9-1.6)$ & 0.029 \\
\hline Supraglottic score & $2.0(1.8-2.3)$ & $2.0(1.4-2.6)$ & 1 & $1.6(1.3-2.0)$ & 0.075 \\
\hline CLE-scores (total) shortly after IMT ${ }^{\mathrm{a}}$ & $1.8(1.4-2.2)$ & $3.4(2.2-4.6)$ & $<0.001$ & Not done & \\
\hline Glottic score & $0.3(0.1-0.6)$ & $1.6(0.6-2.6)$ & $<0.001$ & Not done & \\
\hline Supraglottic score & $1.5(1.2-1.8)$ & $1.8(1.0-2.5)$ & 0.346 & Not done & \\
\hline \multicolumn{6}{|l|}{ The level of laryngeal obstruction, $n$} \\
\hline Supraglottic $>$ glottic & 9 & 3 & & 11 & \\
\hline Supraglottic $<$ glottic & 3 & 2 & & 6 & \\
\hline Supraglottic $=$ glottic & 11 & 4 & & 6 & \\
\hline
\end{tabular}

All subjects had received information and breathing advice (IBA) and one group had additionally received inspiratory muscle training (IBA + IMT group). The IBA + IMT group is split according to reports of subjective improvement 2-4 weeks after IMT

Figures are numbers $(n)$ or means (95\% confidence intervals)

$I M T$ inspiratory muscle training, IBA information and breathing advice, $C I$ confidence interval, CLE-score continuous laryngoscopy exercise score, grading of laryngeal obstruction according to Maat et al. [1],

${ }^{a}$ All subjects in the IBA + IMT group completed a new CLE-test 2-4 weeks after six weeks of IMT for evaluation

${ }^{\mathrm{b}}$ Comparison of scores with Student's $t$ test between subjects with subjective improvement shortly after IMT and no subjective improvement shortly after IMT

${ }^{\mathrm{c}}$ Comparison of scores with Student's $t$ test between IBA + IMT group (combined subjective improvement shortly after IMT and no subjective improvement, not tabulated) and the IBA-group

Fig. 4 Laryngeal obstruction (evaluated by CLE-scores at glottic and supraglottic level) in subjects diagnosed with exercise induced laryngeal obstruction (EILO) at Haukeland University Hospital and treated with information and breathing advice (IBA) and additionally received 6 weeks of inspiratory muscle training (IBA + IMT group). The group is split according to reports of subjective improvement $2-4$ weeks after IMT. $P$ values refer to mean change of glottic and supraglottic CLEscores after 6 weeks of IMT

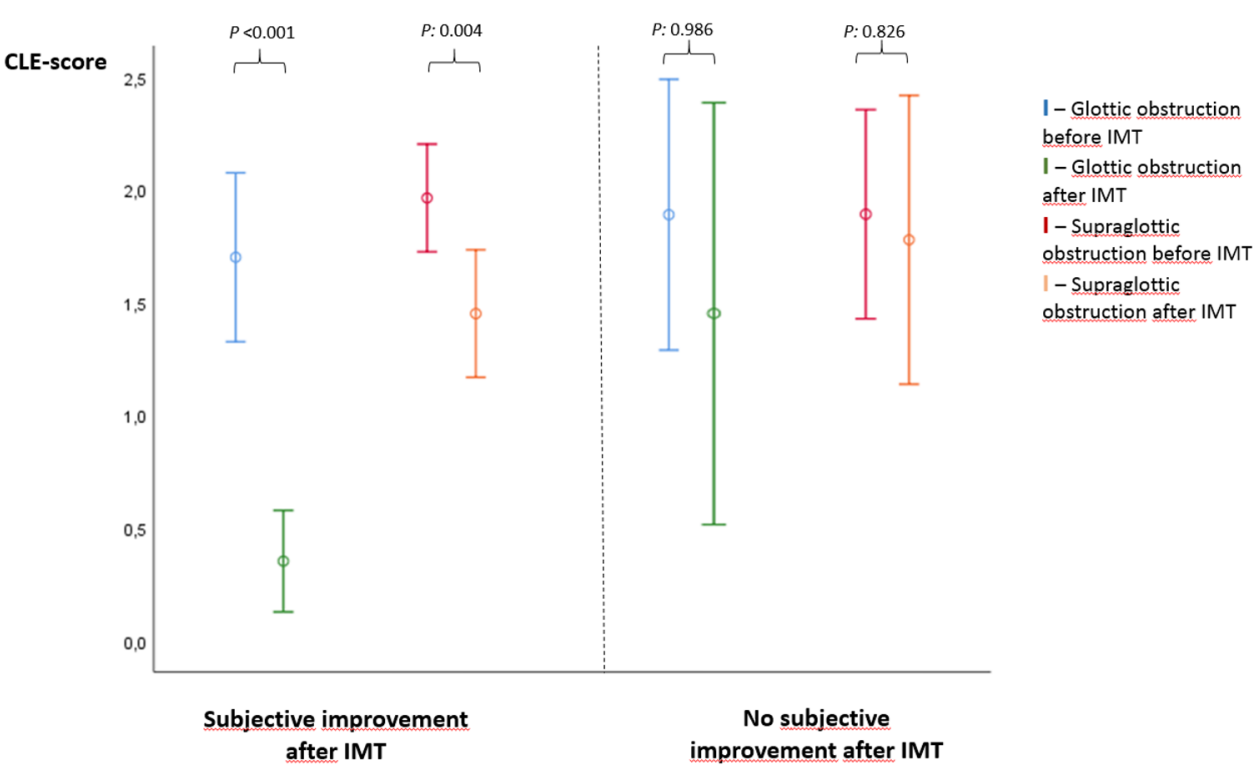

relation to EILO, and relationships between answers therefore challenging to elucidate in some instances. However, key items were selected from sources validated in EILO or other respiratory contexts [31, 32]. Diagnostic characteristics from the time of the diagnosis were similar between responders and non-responders; however, we had no way of establishing their treatment motivation. The questionnaire required the participants to report utilization of other treatment modalities (for example psychological counselling) during the years that had passed since they had been diagnosed. Our response rate was in line with some [33] and lower than other studies [34-36], but the study still 
Table 3 Self-reported data obtained at diagnosis and at follow-up 4-6 years after being diagnosed with exercise induced laryngeal obstruction (EILO) at Haukeland University Hospital

\begin{tabular}{|c|c|c|c|c|c|c|c|}
\hline \multirow{3}{*}{$\begin{array}{l}\text { Questions asked on exercise related issues at follow-up } \\
\text { 4-6 years after diagnosis }\end{array}$} & \multicolumn{3}{|l|}{$\mathrm{IBA}+\mathrm{IMT}$} & \multicolumn{3}{|l|}{ IBA } & \multirow[t]{3}{*}{$P$ value $^{\mathrm{b}}$} \\
\hline & \multicolumn{2}{|l|}{$n=32$} & \multirow[t]{2}{*}{$P$ value $^{\mathrm{a}}$} & \multicolumn{2}{|l|}{$n=23$} & \multirow[t]{2}{*}{$P$ value $^{\mathrm{a}}$} & \\
\hline & At diagnosis & At follow-up & & At diagnosis & At follow-up & & \\
\hline Q1. I have trouble breathing in & $4.2(3.8-4.6)$ & $2.5(2.1-3.0)$ & $<0.001$ & $4.3(3.9-4.8)$ & $2.3(1.8-2.7)$ & $<0.001$ & 0.46 \\
\hline Q3. I feel tightness/pain in my throat & $3.6(3.1-4.2)$ & $2.3(1.7-2.8)$ & 0.002 & $3.9(3.3-4.6)$ & $2.1(1.6-2.7)$ & $<0.001$ & 0.486 \\
\hline Q7. I feel like I'm being choked & $3.7(3.1-4.2)$ & $2.0(1.5-2.5)$ & $<0.001$ & $3.3(2.6-4.1)$ & $1.8(1.3-2.3)$ & $<0.001$ & 0.528 \\
\hline $\begin{array}{l}\text { Q8. I become dizzy, nauseous and feel like I'm going } \\
\text { to faint }\end{array}$ & $2.8(2.3-3.4)$ & $1.6(1.2-1.9)$ & $<0.001$ & $2.4(1.7-3.2)$ & $1.5(1.0-2.0)$ & 0.008 & 0.11 \\
\hline Q9. The symptoms come on fast & $3.8(3.3-4.3)$ & $2.4(1.9-2.8)$ & $<0.001$ & $3.9(3.4-4.4)$ & $1.9(1.4-2.5)$ & $<0.001$ & 0.167 \\
\hline Q11. I feel panic & $2.9(2.2-3.6)$ & $1.3(1.1-1.6)$ & $<0.001$ & $2.6(1.8-3.4)$ & $1.7(1.1-2.3)$ & 0.009 & 0.268 \\
\hline $\begin{array}{l}\text { Q12. I have problems breathing when I am physically } \\
\text { active }\end{array}$ & $4.0(3.5-4.5)$ & $2.9(2.3-3.4)$ & 0.002 & $4.1(3.6-4.7)$ & $2.6(2.0-3.1)$ & $<0.001$ & 0.201 \\
\hline $\begin{array}{l}\text { Q13. I can hear unusual or wheezing sounds when I } \\
\text { breathe }\end{array}$ & $3.9(3.4-4.5)$ & $2.3(1.8-2.7)$ & $<0.001$ & $3.2(2.3-4.1)$ & $1.8(1.4-2.3)$ & 0.001 & 0.754 \\
\hline $\begin{array}{l}\text { Q14. My symptoms prevent me from training/exercis- } \\
\text { ing }\end{array}$ & $3.0(2.4-3.6)$ & $1.6(1.3-2.0)$ & $<0.001$ & $2.7(2.1-3.3)$ & $1.6(1.0-2.2)$ & $<0.001$ & 0.119 \\
\hline Q15. I become afraid when I get symptoms & $2.8(2.1-3.6)$ & $1.2(1.0-1.4)$ & $<0.001$ & $2.6(1.8-3.3)$ & $1.6(1.0-2.2)$ & 0.002 & 0.171 \\
\hline $\begin{array}{l}\text { Q16. My symptoms prevent me pushing myself when } \\
\text { exercising }\end{array}$ & $3.2(2.6-3.8)$ & $2.0(1.6-2.4)$ & $<0.001$ & $3.1(2.4-3.8)$ & $1.7(1.0-2.3)$ & 0.002 & 0.174 \\
\hline Q18. I can control my symptoms when I get them & $2.6(2.0-3.2)$ & $3.3(2.9-3.8)$ & 0.018 & $2.3(1.7-2.8)$ & $2.8(2.1-3.6)$ & 0.064 & 0.299 \\
\hline $\begin{array}{l}\text { Q-B.2: How much do your breathing problems effect } \\
\text { you NOW? }\end{array}$ & $2.9(2.6-3.2)$ & $2.0(1.7-2.3)$ & $<0.001$ & $2.9(2.4-3.5)$ & $1.8(1.3-2.3)$ & $<0.001$ & 0.436 \\
\hline $\begin{array}{l}\text { Q-B.1: How much did your breathing problems effect } \\
\text { you before? }\end{array}$ & - & $3.3(3.1-3.6)$ & $0.016^{\mathrm{c}}$ & - & $3.1(2.6-3.5)$ & $0.426^{\mathrm{c}}$ & \\
\hline
\end{tabular}

All participants had received information and breathing advice (IBA) and one group had additionally received inspiratory muscle training (IBA + IMT group)

Figures are means (95\% confidence intervals)

Answers to Q1-Q18 were based on ordinal scale from 1 to 5: 1: never, 2: occasionally, 3: often, 4: nearly always, 5: always

Answers to Q-B1-2 were based on scale from 1 to 5: 1: not at all, 2: a little, 3: quite a lot, 4: a great amount, 5: crippling

${ }^{a}$ Compares means in each group at diagnosis versus at follow-up with student's paired $t$ test

${ }^{\mathrm{b}}$ Compares means at follow-up to each question between the IBA + IMT group and the IBA-group with student $t$ test

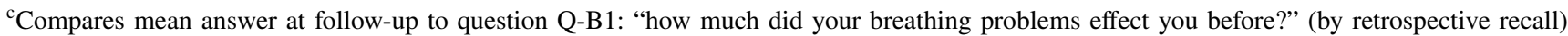
and at time of diagnosis to QB-2: "how much do your breathing problems effect you?" with student's paired $t$ test, mean difference was in IBA + IMT group: -0.40 and in IBA group -0.17

represents one of the few studies evaluating symptoms from EILO over time.

\section{The challenges of self-reported symptoms and their relation to objective findings}

Dyspnea is a complex and highly subjective feature [15], consisting of both a sensation of breathlessness and an emotional interpretation [37], i.e., the individual's coping mechanisms to handle the breathlessness. As dyspnea can only be perceived by the individual who experience it, assessment must rest on self-report [38]. The questionnaire used in this study, addressed domains of sensory-perceptual experience and symptom impact or burden, as recommended when assessing dyspnea [38]. We know from other studies that self-reported instruments tend to overestimate intensity and duration of physical activity [39], and that poor physical condition often explain self-reported exercise-induced dyspnea [40], factors we could not control for in our study. Bias by recall or in terms of altered positive and negative expectations related to the experience of symptoms over time, may also be of importance. This mechanism may have been involved in the IBA+IMT-group, where the significance of the breathing problem was scored lower when asked at diagnosis, compared to when retrospectively confronted with the same question at follow-up (Table 3).

The study highlights numerous challenges relating to subjective symptom-reporting versus objective findings in general [41]. Specifically, the study underlines that individuals' perception of dyspnea do not necessarily correspond 
Table 4 Self-reported data obtained at follow-up 4-6 years after being diagnosed with exercise induced laryngeal obstruction (EILO) at Haukeland University Hospital

\begin{tabular}{|c|c|c|c|c|}
\hline \multirow{2}{*}{$\begin{array}{l}\text { Questions asked at follow-up 4-6 years after diagnosis } \\
\text { The IBA + IMT group split according to responses at } \\
\text { assessment 2-4 weeks after IMT }\end{array}$} & \multicolumn{2}{|l|}{ IBA+ IMT } & \multirow{2}{*}{$\begin{array}{l}\text { IBA } \\
n=23\end{array}$} & \multirow[t]{2}{*}{$P$ value $^{\mathrm{a}}$} \\
\hline & $\begin{array}{l}\text { Subjective improvement } \\
2-4 \text { weeks after IMT } \\
(n=23)\end{array}$ & $\begin{array}{l}\text { No-subjective improvement } \\
2-4 \text { weeks after IMT }(n=9)\end{array}$ & & \\
\hline $\begin{array}{l}\text { Reported as numbers yes/no or unsure } \\
\text { "Since time of diagnosis" }\end{array}$ & Yes/no or unsure & Yes/no or unsure & Yes/no or unsure & \\
\hline Q-A.1:"The breathing problem have got worse" & $0 / 23$ & $1 / 8$ & $0 / 23$ & 0.240 \\
\hline Q-A.2: "The breathing problem is unchanged" & $6 / 17$ & $0 / 7$ & $9 / 14$ & 0.296 \\
\hline $\begin{array}{l}\text { Q-A.4: "I have less breathing problems because I am } \\
\text { less active" }\end{array}$ & $11 / 12$ & $2 / 7$ & $10 / 13$ & 0.884 \\
\hline Q-A.7: "The breathing problem has improved" & $13 / 10$ & $7 / 2$ & $9 / 14$ & 0.183 \\
\hline Q-A.8: "I no longer have a breathing problem" & $3 / 20$ & $2 / 7$ & $3 / 20$ & 0.121 \\
\hline
\end{tabular}

All participants had received information and breathing advice (IBA) and one group had additionally received inspiratory muscle training (IBA + IMT group). The IBA + IMT group is split according to reports of subjective improvement 2-4 weeks after IMT

$I B A$ information and physician guided breathing advice), $I B A+I M T$ received IBA and additionally received inspiratory muscle training (IMT) for 6 weeks

${ }^{a}$ Comparison of scores with Mann- $U$-Whitney test between IBA + IMT group (combined subjective improvement shortly after IMT and no subjective improvement, not tabulated) and the IBA-group

to their CLE-scores. Symptom scores at diagnosis were similar in both groups, despite more advanced laryngeal obstruction (higher CLE-scores) in the IBA + IMT-group. Similar levels of self-reported symptoms at diagnosis facilitated a direct comparison at the 4-6 years follow-up, when symptom descriptions were still similar between the two groups, although at lower levels. Interestingly, at the CLE re-evaluation shortly after the IMT, subjective improvements of self-reported symptoms were associated with improved CLE-scores. However, this initial short-term response was seemingly unrelated to symptom scores 4-6 years later. A better understanding of the diagnostic implications and interactions between laryngeal obstruction and individuals' perception of dyspnea is clearly an unmet need in this field of respiratory medicine $[5,16]$.

\section{The age and gender distribution of EILO in this study and in general}

Participants were recruited from the Bergen EILO-register, which has a high cover ratio, suggesting they were representative for typical EILO patients referred for second-line care. This notion is supported by an age distribution in line with most clinical EILO studies [2]. The participants of the IBA + IMT-group was slightly older than in the IBA-group, perhaps reflecting that older patients felt more motivated for second-line therapy. The female predominance was even higher than reported by others $[2,12]$, especially in the IBA + IMT-group. Although poorly investigated, genderdependent anatomical changes of the larynx during puberty suggest a smaller inner diameter of the larynx in females that may explain a female predominance in young adults with EILO [42]. Females also tend to report higher symptom scores in health surveys [39], a factor that might contribute to more females considered for second-line therapy for EILO.

\section{Development of EILO and physical activity}

At follow-up 4-6 years after diagnosis, most participants had reduced their level of physical activity, and about half the participants reported that this was the cause of experiencing less breathing problems. The typical age for the debut of EILO corresponds to a period when physical activity often starts to decline $[43,44]$. We do not know the natural course of EILO, but the few studies investigating this issue suggest that EILO persists over time [34-36]. This is consistent with our findings, with only a few participants reporting full resolution of their breathing problems. A study that re-examined individuals with EILO after 20 years of age, found that CLE-scores tended to be unchanged, paralleled by a decline of both physical activity and symptom severity [35]. These studies and our findings, indicate that a decline of self-reported respiratory symptoms in patients with EILO may be linked to a decline in the level of physical activity; i.e., not an improvement of the condition per se, but simply linked to a vanishing inducer (exercise) [24, 35, 36]. Given the relatively high prevalence of EILO, proper handling of these young individuals seems important also from a public health perspective, as it might contribute to maintenance of a healthy level of physical activity [43]. 


\section{Information and breathing advice versus inspiratory muscle training}

Several authors have suggested that IBA facilitates control of EILO symptoms [7, 19], and that IMT may have an added positive influence [27]. The present study might be used to support these views, as symptoms shortly after IBA + IMT had improved in a majority, and these improvements were associated with better CLE-scores. As already discussed, this must be tested in controlled studies, as short-term contributions from IBA and IMT cannot readily be distinguished in our study design. Moreover, the improvements of self-reported symptoms after 4-6 years contribute to a positive view on both conservative treatment tools. We found no significant difference long-term between those who received only IBA and those receiving additionally 6 weeks of IMT. The IBA and IMT incorporates some of the work which in other countries might have been provided by speech and language therapists, but was provided by physicians during only one session and at rest. We were not present when participants attempted to "translate" this experience into real-life exercise at home, aspects that may have hampered long-term effects [5]. We know for example, that muscle strength is reversible and changes over time [21]. One may speculate that repeated training sessions would contribute to maintenance of the positive short-term results obtained after IBA + IMT as reported when applied in patients with paradoxical vocal fold motion at rest [45]. This should be investigated in future controlled studies.

\section{EILO subgroups and implications for choice of treatment}

Tailored treatment based on laryngeal findings still rests on weak evidence, except in severe supraglottic EILO where laser surgery has been reported successful [20]. Subjective improvement shortly after IBA + IMT was associated with better CLEscores, particularly at the glottic level, a finding substantiating the hypothesis that IBA + IMT mainly targets glottic obstruction [27]. Thus, it is reasonable to assume from this and previous studies that some EILO subgroups may not benefit from IBA + IMT. Indeed, a case-report suggests that IMT might even be counterproductive in severe supraglottic EILO [26]. A somewhat disappointing finding was that CLE-scores at diagnosis were not associated with self-reported symptoms 2-4 weeks after IBA + IMT, nor at follow-up 4-6 years later. Thus, diagnostic CLE-scores seemingly do not predict who will respond to $\mathrm{IBA}+\mathrm{IMT}$.

\section{Conclusion}

Self-reported symptoms and laryngeal findings had improved 2-4 weeks after treatment with IBA plus 6 weeks of IMT. After 4-6 years, self-reported symptoms were improved compared to at time of diagnosis; however, irrespective of initial treatment and findings 2-4 weeks after IBA + IMT. Full symptom resolution was rare, and respiratory problems still disturbed most participants during physical activity. Future studies should investigate if follow-up schemes after conservative treatment, including retraining sessions with IMT, will lead to strengthened and sustained improvements.

Supplementary Information The online version contains supplementary material available at https://doi.org/10.1007/s00405-021-07214-5.

Acknowledgements The authors have no financial or non-financial interests that are directly or indirectly related to the work submitted for publication to disclose.

Author contributions All authors contributed to the study conception and design. Material preparation, data collection and analysis were performed by AS and in collaboration with the other authors. The first draft of the manuscript was written by AS and all authors commented on previous versions of the manuscript. All authors read and approved the final manuscript.

Funding Open access funding provided by University of Bergen (incl Haukeland University Hospital). Research grant for Astrid Sandnes was received by Innlandet Hospital Trust, Norway. Research support in form of salaries to the authors and equipment was received by Haukeland University Hospital.

\section{Declarations}

Conflict of interest The authors have no conflicts of interest to disclose. Haukeland University Hospital owns parts of US patent No. $11 / 134551$, protecting the commercial rights of the CLE test.

Ethics approval The study was approved by the Regional Ethics Committee (REK number: 2016/1898), date 24 October 2018. The study was performed in accordance with the ethical standards as laid down in the 1964 Declaration of Helsinki and its later amendments or comparable ethical standards. All participants provided informed written consent.

Open Access This article is licensed under a Creative Commons Attribution 4.0 International License, which permits use, sharing, adaptation, distribution and reproduction in any medium or format, as long as you give appropriate credit to the original author(s) and the source, provide a link to the Creative Commons licence, and indicate if changes were made. The images or other third party material in this article are included in the article's Creative Commons licence, unless indicated otherwise in a credit line to the material. If material is not included in the article's Creative Commons licence and your intended use is not permitted by statutory regulation or exceeds the permitted use, you will need to obtain permission directly from the copyright holder. To view a copy of this licence, visit http://creativecommons.org/licenses/by/4.0/. 


\section{References}

1. Roksund OD et al (2017) Exercise inducible laryngeal obstruction: diagnostics and management. Paediatr Respir Rev 21:86-94

2. Christensen PM et al (2011) Exercise-induced laryngeal obstructions: prevalence and symptoms in the general public. Eur Arch Otorhinolaryngol 268(9):1313-1319

3. Johansson $\mathrm{H}$ et al (2015) Prevalence of exercise-induced bronchoconstriction and exercise-induced laryngeal obstruction in a general adolescent population. Thorax 70(1):57-63

4. Liyanagedera S, McLeod R, Elhassan HA (2017) Exercise induced laryngeal obstruction: a review of diagnosis and management. Eur Arch Otorhinolaryngol 274(4):1781-1789

5. Hull JH, Godbout K, Boulet LP (2020) Exercise-associated dyspnea and stridor: thinking beyond asthma. J Allergy Clin Immunol Pract 8:2202-2208

6. Hicks M, Brugman SM, Katial R (2008) Vocal cord dysfunction/ paradoxical vocal fold motion. Prim Care 35(1):81-103, vii

7. Shembel AC, Sandage MJ, Verdolini Abbott K (2017) Episodic laryngeal breathing disorders: literature review and proposal of preliminary theoretical framework. J Voice 31(1):125 e7-125 e16

8. Yeatts $\mathrm{K}$ et al (2003) Health consequences associated with frequent wheezing in adolescents without asthma diagnosis. Eur Respir J 22(5):781-786

9. Johansson H et al (2014) Exercise-induced dyspnea is a problem among the general adolescent population. Respir Med 108(6):852-858

10. Mirza KK, Walsted ES, Backer V (2017) Ergospirometry with concurrent fibre optic laryngoscopy: a randomised crossover study. Eur Clin Respir J 4(1):1399033

11. Heimdal JH et al (2006) Continuous laryngoscopy exercise test: a method for visualizing laryngeal dysfunction during exercise. Laryngoscope 116(1):52-57

12. Halvorsen TW, Bucca C, Bush A, Cantarella G, Friedrich G, Felix JF, Herth FJF, Hull JH, Jung H, Maat R, Nordang L, Remacle M, Rasmussen JA, Heimdal J-H (2017) Inducible laryngeal obstruction: an official joint European Respiratory Society and European Laryngological Society statement. Eur Respir J 50(3):1602221

13. Maat RC et al (2009) Audiovisual assessment of exercise-induced laryngeal obstruction: reliability and validity of observations. Eur Arch Otorhinolaryngol 266(12):1929-1936

14. Depiazzi J, Everard ML (2016) Dysfunctional breathing and reaching one's physiological limit as causes of exercise-induced dyspnoea. Breathe (Sheff) 12(2):120-129

15. Yorke $\mathbf{J}$ et al (2010) Quantification of dyspnoea using descriptors: development and initial testing of the Dyspnoea-12. Thorax 65(1):21-26

16. Norlander K et al (2020) Differences in laryngeal movements during exercise in healthy and dyspnoeic adolescents. Int J Pediatr Otorhinolaryngol 129:109765

17. Shaffer M et al (2018) Speech-language pathology as a primary treatment for exercise-induced laryngeal obstruction. Immunol Allergy Clin N Am 38(2):293-302

18. Rameau A et al (2012) Multidisciplinary approach to vocal cord dysfunction diagnosis and treatment in one session: a single institutional outcome study. Int J Pediatr Otorhinolaryngol 76(1):31-35

19. Johnston KL et al (2018) The Olin EILOBI breathing techniques: description and initial case series of novel respiratory retraining strategies for athletes with exercise-induced laryngeal obstruction. J Voice 32(6):698-704

20. Siewers K, Backer V, Walsted ES (2019) A systematic review of surgical treatment for supraglottic exercise-induced laryngeal obstruction. Laryngoscope Investig Otolaryngol 4(2):227-233
21. Leith DE, Bradley M (1976) Ventilatory muscle strength and endurance training. J Appl Physiol 41(4):508-516

22. Sandnes A et al (2013) Laryngeal movements during inspiratory muscle training in healthy subjects. J Voice 27(4):448-453

23. Brancatisano TP, Dodd DS, Engel LA (1984) Respiratory activity of posterior cricoarytenoid muscle and vocal cords in humans. J Appl Physiol Respir Environ Exerc Physiol 57(4):1143-1149

24. Mathers-Schmidt BA, Brilla LR (2005) Inspiratory muscle training in exercise-induced paradoxical vocal fold motion. J Voice 19(4):635-644

25. Dickinson J, Whyte G, McConnell A (2007) Inspiratory muscle training: a simple cost-effective treatment for inspiratory stridor. Br J Sports Med 41(10):694-695 (discussion 695)

26. Clemm HSH et al (2018) The heterogeneity of exerciseinduced laryngeal obstruction. Am J Respir Crit Care Med 197(8):1068-1069

27. Sandnes A, Clemm HH, Hilland M, Vollsæter M, Heimdal JHH, Eide GE, Halvorsen T, Roksund O (2019) Exercise-induced laryngeal obstruction in athletes treated with inspiratory muscle training. BMJ Open Sport Exerc Med 5(1):e000436

28. Gaylord JN, Peterson S, Ray J (2020) Struggling to breathe: inspiratory muscle training in adolescent athletes. J Voice 14;S08921997(20)30172-7. https://doi.org/10.1016/j.jvoice.2020.05.002

29. Laveneziana P et al (2019) ERS statement on respiratory muscle testing at rest and during exercise. Eur Respir J 53(6):1801214

30. Lydersen $S$ (2015) Statistical review: frequently given comments. Ann Rheum Dis 74(2):323-325

31. Fowler SJ et al (2015) The VCDQ-a Questionnaire for symptom monitoring in vocal cord dysfunction. Clin Exp Allergy 45(9):1406-1411

32. Gartner-Schmidt JL et al (2014) Development and validation of the Dyspnea Index (DI): a severity index for upper airway-related dyspnea. J Voice 28(6):775-782

33. Johansson H, Norlander K, Malinovschi A (2019) Increased prevalence of exercise-induced airway symptoms - a five-year followup from adolescence to young adulthood. Respir Med 154:76-81

34. Doshi DR, Weinberger MM (2006) Long-term outcome of vocal cord dysfunction. Ann Allergy Asthma Immunol 96(6):794-799

35. Maat RC et al (2011) Exercise-induced laryngeal obstruction: natural history and effect of surgical treatment. Eur Arch Otorhinolaryngol 268(10):1485-1492

36. Norlander K et al (2015) Surgical treatment is effective in severe cases of exercise-induced laryngeal obstruction: a follow-up study. Acta Otolaryngol 135(11):1152-1159

37. Banzett RB et al (2015) Multidimensional dyspnea profile: an instrument for clinical and laboratory research. Eur Respir J 45(6):1681-1691

38. Parshall MB et al (2012) An official American Thoracic Society statement: update on the mechanisms, assessment, and management of dyspnea. Am J Respir Crit Care Med 185(4):435-452

39. Ekelund U, Tomkinson G, Armstrong N (2011) What proportion of youth are physically active? Measurements issues, levels and recent time trends. Br J Sports Med 45(11):859-865

40. Abu-Hasan M, Tannous B, Weinberger M (2005) Exerciseinduced dyspnea in children and adolescents: if not asthma then what? Ann Allergy Asthma Immunol 94(3):366-371

41. Hjermstad MJ et al (2011) Studies comparing Numerical Rating Scales, Verbal Rating Scales, and Visual Analogue Scales for assessment of pain intensity in adults: a systematic literature review. J Pain Symptom Manage 41(6): 1073-1093

42. Wysocki J et al (2008) Measurements of pre- and postpubertal human larynx: a cadaver study. Surg Radiol Anat 30(3):191-199

43. Corder K, Ogilvie D, van Sluijs EM (2009) Invited commentary: Physical activity over the life course-whose behavior changes, when, and why? Am J Epidemiol 170(9):1078-1081 (discussion 1082-1083) 
44. Dumith SC et al (2011) Physical activity change during adolescence: a systematic review and a pooled analysis. Int J Epidemiol 40(3):685-698

45. Nacci A et al (2011) Respiratory retraining therapy in long-term treatment of paradoxical vocal fold dysfunction. Folia Phoniatr Logop 63(3):134-141
Publisher's Note Springer Nature remains neutral with regard to jurisdictional claims in published maps and institutional affiliations. 